\title{
Potential application of persulfate and simulated sunlight radiation on azithromycin removal
}

\author{
Brandon A. Ospino-Atehortúa ${ }^{1,2}$, Henry Zúñiga-Benítez ${ }^{1,2^{\dagger}}$, Gustavo A. Peñuela ${ }^{2}$ \\ ${ }^{1}$ Departamento de Ingeniería Química, Facultad de Ingeniería, Universidad de Antioquia UdeA. Calle 70 \# 52-21, Medellín, Colombia \\ ${ }^{2}$ Grupo GDCON, Facultad de Ingeniería, Sede de Investigación Universitaria (SIU), Universidad de Antioquia UdeA, Calle 70 \# 52 -21, Medellín, \\ Colombia
}

\begin{abstract}
Azithromycin (AZT) is a macrolide antibiotic whose presence in different bodies of water has been reported. This implies that conventional treatment systems are not able for AZT removal. This paper presents the main results regarding the potential use of simulated sunlight and persulfate (PS) on the removal of AZT. The effects of the solution $\mathrm{pH}$ and the concentration of PS were evaluated considering a face centered, central composite experimental design. Under optimized experimental conditions, it was possible to reach an AZT elimination around $70.0 \%$, and $\sim 30.0 \%$ reduction of the total organic matter after $120 \mathrm{~min}$ of reaction. Additionally, it was established that basic $\mathrm{pH}$ conditions favor AZT removal, and high doses of PS could have an inhibitory effect on the reaction due to a radical scavenging phenomenon. The roles of $\mathrm{SO}_{4} \cdot{ }^{-}$and $\mathrm{OH}^{\bullet}$ radicals on the reaction were evaluated by conducting tests under the presence of ethanol and tert-Butyl alcohol. In this manner, $\mathrm{OH} \bullet$ radicals seem to be the main oxidizing species of AZT. Finally, the evaluation of the effect of the initial pollutant concentration allowed to establish that a pseudo first-order reaction kinetics model can be used to describe the AZT elimination under the evaluated experimental conditions.
\end{abstract}

Keywords: Advanced oxidation, Antibiotics, Azithromycin, Sulfate radicals, Sunlight, Wastewater treatment

\section{Introduction}

Pharmaceutical industry development has led to the introduction of different kinds of chemical compounds into bodies of water. A particular scenario is the presence of antibiotics in environmental compartments due to its incomplete absorption after being used to treat bacterial infections. In addition, in most cases, conventional wastewater treatment plants do not have the appropriate design to remove antibiotics and other types of pharmaceutical compounds promoting their discharge into aquatic environments, and representing a potential risk of bacterial resistance generation [1-3].

Azithromycin $\left(\mathrm{C}_{38} \mathrm{H}_{72} \mathrm{~N}_{2} \mathrm{O}_{12}\right.$, AZT $)$ is a broad-spectrum macrolide antibiotic employed in the treatment of different types of respiratory, gastric, and sexually transmitted diseases [4]. This has promoted not only its extensive use but also that its presence in the effluents of wastewater treatment plants and different natural bodies of water has been reported [5].

Some of the alternatives that have been evaluated for the removal of antibiotics from environmental matrices are the advanced oxida-

This is an Open Access article distributed under the terms of the Creative Commons Attribution Non-Commercial License (http://creativecommons.org/licenses/by-nc/3.0/) which permits unrestricted non-commercial use, distribution, and reproduction in any medium, provided the original work is properly cited.

Copyright (C) 2021 Korean Society of Environmental Engineers tion technologies (AOT). In particular, sulfate radical-based AOT represent an effective option for the elimination of organic micro-pollutants present in water. In this sense, it has been reported that sulfate radical $\left(\mathrm{SO}_{4}{ }^{-}\right)$has a strong oxidation capacity, and could react with many complex organic contaminants including polychlorinated biphenyls (PCBs), aromatic compounds and dyes [6-8].

Activation of persulfate (PS) by heat, transition metals, ultrasonic, and light radiation are some of the most common ways to generate $\mathrm{SO}_{4}^{-} \bullet$ [9]. In this way, different authors have evaluated the use of PS and sunlight radiation for the generation of $\mathrm{SO}_{4}{ }^{-}$and the removal of organic pollutants [10-12]. Eq. (1) shows the activation of PS by light radiation to generate $\mathrm{SO}_{4}^{-} \bullet$. Besides, $\mathrm{SO}_{4}^{-} \bullet$ can also be transformed to $\mathrm{OH} \bullet$ (a radical specie with higher oxidizing capacity) according to Eq. (2) [9].

$$
\begin{gathered}
\mathrm{S}_{2} \mathrm{O}_{8}^{2-}+h v \rightarrow 2 \mathrm{SO}_{4}^{-\bullet} \\
\mathrm{SO}_{4}^{-\bullet}+\mathrm{H}_{2} \mathrm{O} \rightarrow \mathrm{SO}_{4}^{2-}+\mathrm{OH}^{\bullet}
\end{gathered}
$$

\footnotetext{
${ }^{\dagger}$ Corresponding author Email: henry.zuniga@udea.edu.co Tel: +57 (4) 21955 37, 35 ORCID: 0000-0002-1243-7213
} 
Different alternatives, such as the combination of UV light and $\mathrm{H}_{2} \mathrm{O}_{2}$, and heterogeneous photocatalysis, have been evaluated for the removal of AZT $[4,13]$. However, to the authors knowledge, no previous studies have assessed the potential application of PS and sunlight in in the AZT elimination from water.

Having into account the above, this paper presents the main results regarding the evaluation of the efficacy of simulated sunlight radiation and PS in the AZT removal from aqueous solutions. In addition, effects of operational parameters such as $\mathrm{pH}$, PS and pollutant initial concentrations were assessed. Changes in the total organic carbon and ions presence in treated solutions were also evaluated.

\section{Material and Methods}

\subsection{Materials}

All chemicals were of at least analytical grade. AZT (98.0\%) was purchased from AK Scientific. Potassium persulfate $\left(\mathrm{K}_{2} \mathrm{~S}_{2} \mathrm{O}_{8}\right)$ supplied by Sigma-Aldrich was employed as PS source. Ethanol (EtOH) and tert-Butyl alcohol (TBA) were supplied by Merck. Concentrated solutions of $\mathrm{NaOH}$ and $\mathrm{HCl}$ were used for modification and control of $\mathrm{pH}$, and methanol and ammonium formate ( $\mathrm{NH}_{4} \mathrm{HCOO}$ ) for chromatographic analysis were of LC/MS grade.

Solutions were freshly prepared using ultra-pure Millipore water (18.2 $\mathrm{M} \Omega \mathrm{cm}, 25^{\circ} \mathrm{C}$ ) (Milli-Q Integral system, Millipore).

\subsection{Photocatalytic System}

$\mathrm{SO}_{4} \bullet$ radicals were generated by activation of PS under simulated sunlight. Experiments were conducted in a sunlight simulator Suntest CPS+ (Atlas) equipped with a $1.5 \mathrm{KW}$ xenon lamp and a light spectrum between 290 and $800 \mathrm{~nm}$. Borosilicate glass flasks containing $50.0 \mathrm{~mL}$ of pollutant were used for light exposition. AZT initial concentration was $1.0 \mathrm{mg} \mathrm{L}^{-1}$ (condition that allowed to satisfy the requirements of the analytical method in terms of precision, accuracy, detection, and quantification limits). Distance from the lamp to the liquid surface was $\sim 15.0 \mathrm{~cm}$, and the liquid depth inside the flasks was $\sim 5.0 \mathrm{~cm}$.

\subsection{Preliminary Experiments}

Some preliminary experiments were carried out to establish the experimental range of solution initial $\mathrm{pH}$ and $\mathrm{K}_{2} \mathrm{~S}_{2} \mathrm{O}_{8}$ concentration that conducts to a significant AZT removal (> 50.0\%). Tests were done varying $\mathrm{K}_{2} \mathrm{~S}_{2} \mathrm{O}_{8}$ dose between 5.0 and $80.0 \mathrm{mg} \mathrm{L}^{-1}$ under natural solution $\mathrm{pH}(\sim 5.2)$ and $30 \mathrm{~min}$ of reaction.

\subsection{Experimental Design}

AZT removal under preliminary test (data not shown) was between 19.7 and $64.4 \%$. A face centered, central composite design was carried out in order to analyze the effects of $\mathrm{pH}$ and $\mathrm{K}_{2} \mathrm{~S}_{2} \mathrm{O}_{8}$ initial concentration on AZT removal after $30 \mathrm{~min}$ of reaction. Statistical analysis was performed using the Statgraphics Centurion 18 software. Table 1 shows the factors and levels evaluated during the experimental design.
Table 1. Factors and Levels Evaluated on AZT Removal Using Simulated Sunlight Radiation and PS

\begin{tabular}{lccc}
\hline Factor & \multicolumn{1}{c}{$\begin{array}{c}\text { Low } \\
\text { level }\end{array}$} & $\begin{array}{c}\text { Medium } \\
\text { level }\end{array}$ & $\begin{array}{c}\text { High } \\
\text { level }\end{array}$ \\
\hline $\begin{array}{c}\mathrm{pH} \\
\mathrm{K}_{2} \mathrm{~S}_{2} \mathrm{O}_{8}\end{array} \begin{array}{c}\text { initial concentration } \\
\left(\mathrm{mg} \mathrm{L}^{-1}\right)\end{array}$ & 3.0 & 6.0 & 9.0 \\
\multicolumn{2}{c|}{2.5} & 5.0 & 7.5 \\
\hline
\end{tabular}

\subsection{Analytical Methods}

AZT quantification was done using an Acquity UPLC system coupled to a triple quadrupole mass spectrometer, and an Acquity UPLC BEH C18 column (Waters Corporation). Information regarding the chromatographic method could be consulted in authors previous reports [14].

Total organic carbon (TOC) and anions (sulfate and nitrate) presence were evaluated considering the methods 526D (High temperature combustion method) and 4110B (Determination of anions by Ion chromatography) established in the Standard Methods for the Examination of Water and Wastewater (2017) [11].

\section{Results and Discussion}

\subsection{Effect of PS Initial Concentration on AZT Removal}

Fig. 1 corresponds to the main effects plot for AZT removal using PS and simulated sunlight radiation. From this figure, it can be seen that the pollutant elimination is enhanced by increasing the PS dose from 2.5 to $\sim 5.0 \mathrm{mg} \mathrm{L}^{-1}$, a situation that could be attributed to a higher generation of reactive species as a result of a high persulfate presence [16]. However, an excessive amount of PS (higher than $5.0 \mathrm{mg} \mathrm{L}^{-1}$ ) could promote an inhibitory effect by $\mathrm{SO}_{4}^{-}$- radical scavenging as it is indicated by Eq. (3) [17].

$$
\mathrm{SO}_{4}^{-\bullet}+\mathrm{S}_{2} \mathrm{O}_{8}^{2-} \rightarrow \mathrm{S}_{2} \mathrm{O}_{8}^{-\bullet}+\mathrm{SO}_{4}^{2-}
$$

\subsection{Effect of Solution pH on AZT Removal}

Fig. 1 also indicates that AZT removal using PS and simulated sunlight radiation increases as the solution initial $\mathrm{pH}$ increased in the range 3.0-9.0. These results could be related to a higher generation of radicals, including active $\mathrm{OH} \bullet$, and probably a greater removal of AZT. According to different authors, under basic conditions organic pollutants removal using activated PS could be favored as result of $\mathrm{SO}_{4}{ }^{-} \bullet$ transformation to $\mathrm{OH} \bullet$ radicals (Eq. (4)). In addition, basic conditions can also activate PS (Eq. (5)) leading to a higher radicals generation in comparison with acidic or neutral conditions $[16,18,19]$.

$$
\begin{gathered}
\mathrm{SO}_{4}^{-\bullet}+\mathrm{OH}^{-} \rightarrow \mathrm{SO}_{4}^{2-}+\mathrm{OH}^{\bullet} \\
\mathrm{S}_{2} \mathrm{O}_{8}^{2-} \stackrel{\mathrm{OH}^{-}}{\longrightarrow} 2 \mathrm{SO}_{4}^{-\bullet}
\end{gathered}
$$

On the other hand, AZT pKa is 8.74, which implies that under acid $\mathrm{pH}$ conditions AZT is protonated, and at $\mathrm{pH} 9.0$ pollutant is mainly in molecular form. In addition, Shokri et al. (2019) [13] 


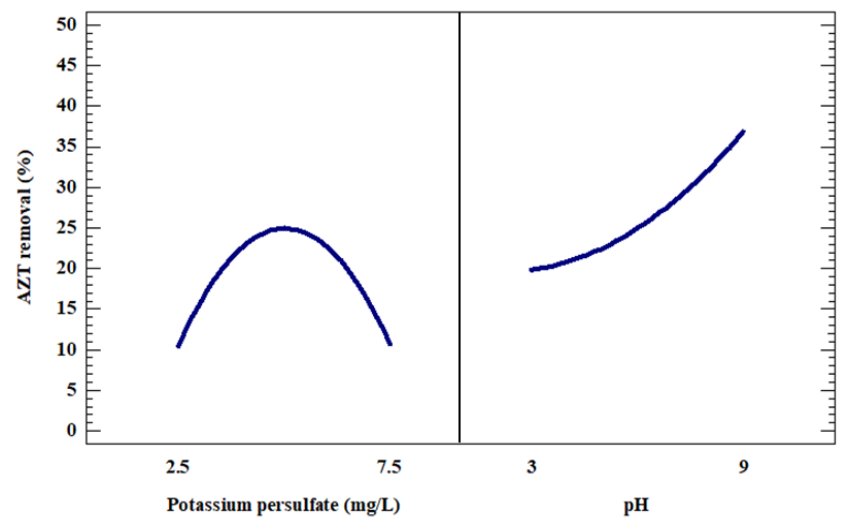

Fig. 1. Main effects plot for AZT removal using simulated sunlight radiation and PS (pollutant initial concentration $1.0 \mathrm{mg} \mathrm{L}^{-1}$, irradiance $500.0 \mathrm{~W} \mathrm{~m}^{-2}$, reaction time $30 \mathrm{~min}$ ).

indicated that AZT tends to attract positive charges. When the solution $\mathrm{pH}$ becomes acidic, AZT will be transformed and removed by the absorption of positive charges.

\subsection{AZT Removal under Optimized Conditions}

Table 2 and Fig. 2 present the results obtained after evaluating the use of PS and simulated sunlight in the removal of AZT under a face centered, central composite experimental design. Additionally, Figure 3 corresponds to the associated Pareto chart which indicates that $\mathrm{pH}$ and the quadratic factor related to the initial concentration of PS are the only significant factors for AZT elimination under the evaluated experimental conditions. Pareto chart shows that the quadratic factor of PS initial concentration has a negative effect on pollutant degradation indicating that PS optimal condition is an intermediate value (very high concentrations of PS could have an inhibitory effect on AZT removal as it was discussed previously). In terms of $\mathrm{pH}$, Pareto chart allows to infer that a higher $\mathrm{pH}$ conducts to a higher AZT extent of degradation.

According to the statistical analysis of the results, the conditions that conduct to a higher AZT removal are $\mathrm{pH} 9.0$ and $5.4 \mathrm{mg}$ $\mathrm{L}^{-1} \mathrm{~K}_{2} \mathrm{~S}_{2} \mathrm{O}_{8}$ initial concentration.

Fig. 4 shows the results regarding the AZT removal under optimized reaction conditions. From this Figure, it can be appreciated that the combination of PS and simulated sunlight is able to remove $\sim 70.0 \%$ of AZT after 120 min of reaction. In addition, control tests indicate that AZT does not suffer any transformation under photolysis (AZT removal using only light radiation), hydrolysis (AZT removal in dark conditions at $\mathrm{pH}$ 9.0) and the action of only PS (AZT removal in dark conditions under optimized concentration of $\mathrm{PS}$ at $\mathrm{pH}$ 9.0).

On the other hand, EtOH and TBA were added to the reaction to determine which radical specie $\left(\mathrm{SO}_{4}{ }^{-} \bullet\right.$ or $\left.\mathrm{OH} \bullet\right)$ was primarily responsible for AZT removal. TBA reacts with $\mathrm{OH} \bullet$ while $\mathrm{EtOH}$ could quench both $\mathrm{OH} \bullet$ and $\mathrm{SO}_{4} \bullet[16,18,20]$. In this way, Fig. 4 indicates that under presence of either TBA or EtOH, AZT extent of elimination decreased. But the inhibitory effect of TBA was higher than that of $\mathrm{EtOH}$. In this way, it can be inferred that both $\mathrm{SO}_{4} \bullet$ and $\mathrm{OH} \bullet$ are present in the reaction, and that the hydroxyl radical was the primary radical specie promoting the AZT removal (higher $\mathrm{pH}$ enhances $\mathrm{OH} \bullet$ formation). One of the advantages of having $\mathrm{OH} \bullet$ in the solution is that this radical is a not selective oxidizing agent that can oxidize almost all kinds of organic compounds, which could enhance not only the AZT elimination but also the generated organic byproducts mineralization.

Table 2. Experimental Design for AZT Removal Using Simulated Sunlight Radiation and PS (pollutant initial concentration $1.0 \mathrm{mg} \mathrm{L}^{-1}$, irradiance $500 \mathrm{~W} \mathrm{~m}^{-2}$, reaction time $30 \mathrm{~min}$ )

\begin{tabular}{|c|c|c|c|}
\hline Test & $\begin{array}{c}\mathrm{K}_{2} \mathrm{~S}_{2} \mathrm{O}_{8} \text { initial concentration } \\
\left(\mathrm{mg} \mathrm{L}^{-1}\right)\end{array}$ & pH & $\begin{array}{c}\text { AZT removal } \\
(\%)\end{array}$ \\
\hline 1 & 2.5 & 6.0 & 13.0 \\
\hline 2 & 5.0 & 3.0 & 17.2 \\
\hline 3 & 7.5 & 3.0 & 3.9 \\
\hline 4 & 2.5 & 9.0 & 15.4 \\
\hline 5 & 5.0 & 6.0 & 27.4 \\
\hline 6 & 7.5 & 9.0 & 27.1 \\
\hline 7 & 5.0 & 6.0 & 20.1 \\
\hline 8 & 5.0 & 6.0 & 27.5 \\
\hline 9 & 7.5 & 6.0 & 8.0 \\
\hline 10 & 2.5 & 3.0 & 9.7 \\
\hline 11 & 5.0 & 9.0 & 39.4 \\
\hline
\end{tabular}

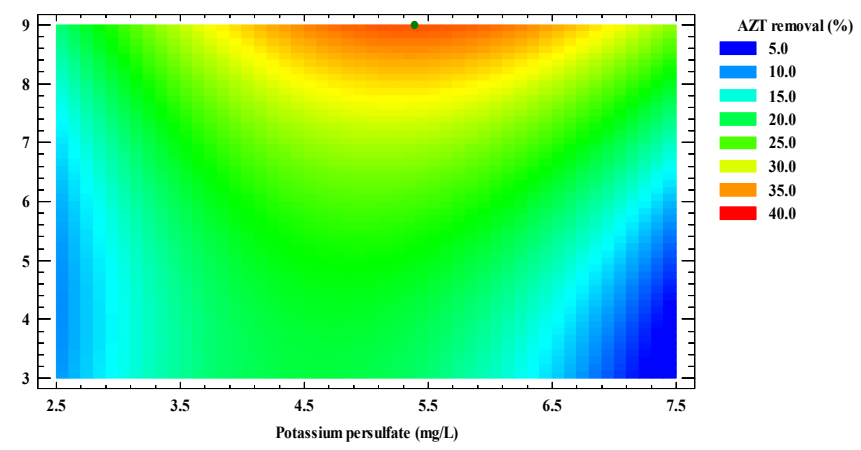

Fig. 2. Surface contour for AZT removal using simulated sunlight radiation and PS (pollutant initial concentration $1.0 \mathrm{mg} \mathrm{L}^{-1}$, irradiance $500.0 \mathrm{~W} \mathrm{~m}^{-2}$, reaction time $\left.30 \mathrm{~min}\right)$.

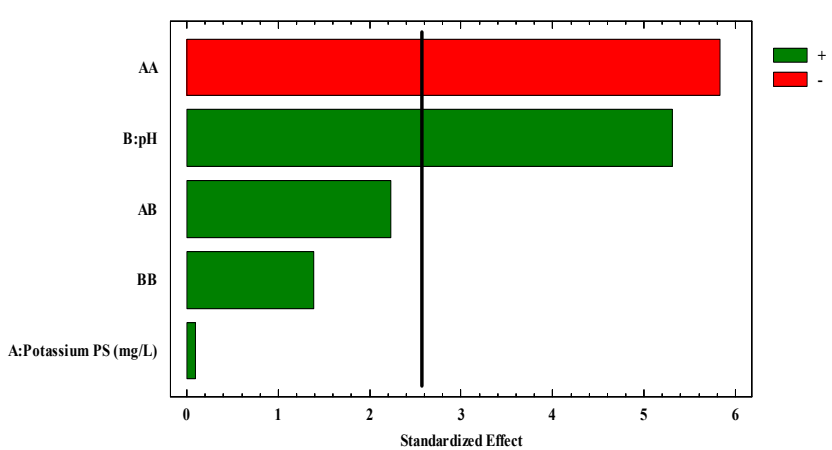

Fig. 3. Pareto chart for AZT removal using simulated sunlight radiation and PS (pollutant initial concentration $1.0 \mathrm{mg} \mathrm{L}^{-1}$, irradiance $500.0 \mathrm{~W} \mathrm{~m}^{-2}$, reaction time $\left.30 \mathrm{~min}\right)$. 


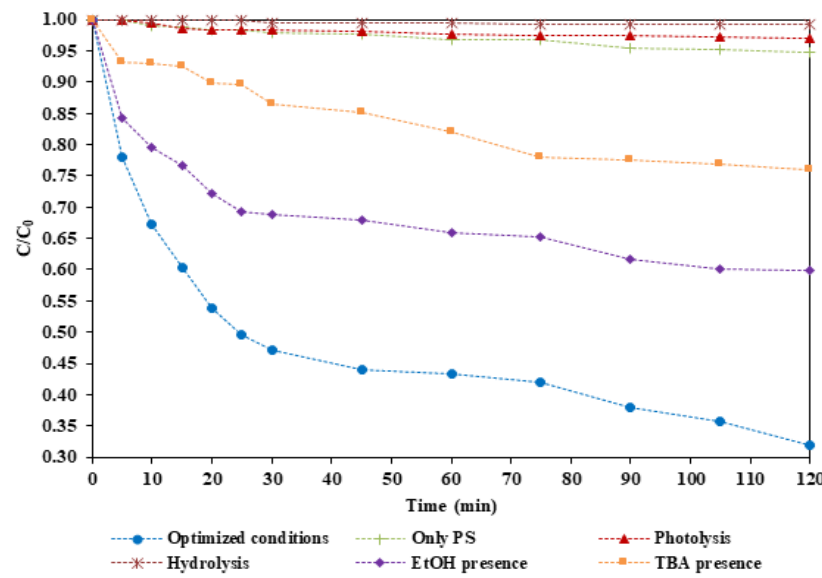

Fig. 4. AZT removal under optimized conditions using simulated sunlight radiation and PS (pollutant initial concentration $1.0 \mathrm{mg} \mathrm{L}^{-1}$, irradiance $500.0 \mathrm{~W} \mathrm{~m}^{-2}, \mathrm{pH}$ 9.0, PS initial concentration $5.4 \mathrm{mg} \mathrm{L}^{-1}$ ).

\subsection{Effect of AZT Initial Concentration}

Fig. 5 shows the results regarding the effect of AZT initial concentration. From Fig. 5 (a) it can be noted that under a higher pollutant initial concentration extent of removal is lower, a situation that could be related to the fact that under higher concentrations of AZT, a higher amount of intermediates or by-products generation could be promoted. In this way, by-products could consume part

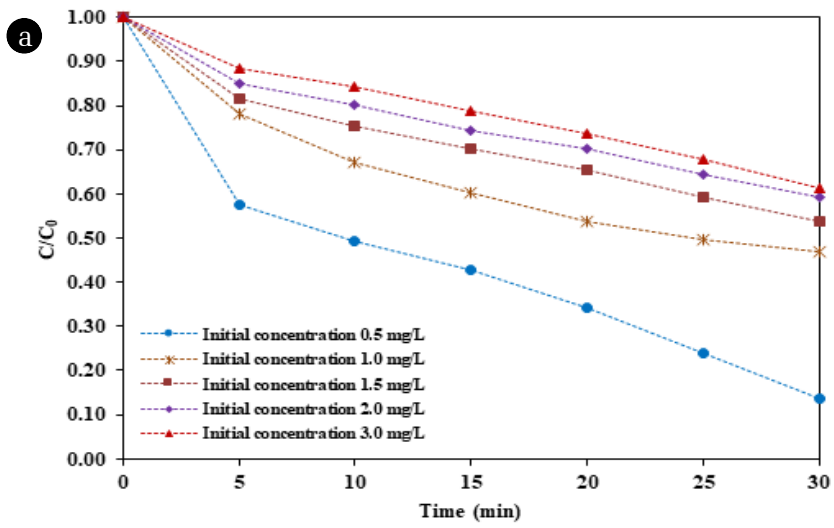

(b)

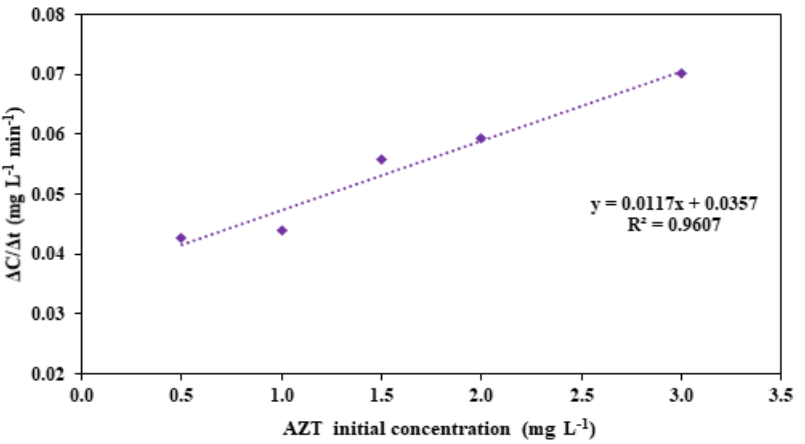

Fig. 5. (a) Pollutant initial concentration effect during AZT removal under optimized conditions using simulated sunlight radiation and PS \& (b) Pseudo first-order reaction kinetics model evaluation (irradiance $500.0 \mathrm{~W} \mathrm{~m}^{-2}, \mathrm{pH}$ 9.0, PS initial concentration $5.4 \mathrm{mg} \mathrm{L}^{-1}$ ). of the photo-generated radicals representing a competitive effect, and then reducing the potential of radicals to oxidise AZT [9].

Organic pollutants removal using sulfate radical-based advanced oxidation processes can be described using a pseudo first-order reaction kinetics model (Eq. (6)) [9, 21].

$$
\mathrm{r}=-\frac{\mathrm{dC}}{\mathrm{dt}}=k_{a p p} \mathrm{C}
$$

$k_{a p p}$ : apparent pseudo first-order kinetic constant

Fig. 5 (b) shows the relationship between AZT initial concentration and the initial degradation rate calculated as $\Delta \mathrm{C} / \Delta \mathrm{t}$ over the first five minutes of reaction. From the figure, it can be noted that experimental data fit the kinetic model adequately $\left(\mathrm{R}^{2}>0.96\right)$ with an $0.117 \mathrm{~min}^{-1}$ associated apparent pseudo first-order kinetic constant.

\subsection{TOC and Anions Presence Evaluation}

Fig. 6 shows the variation of the TOC, $\mathrm{NO}_{3}{ }^{-}$and $\mathrm{SO}_{4}{ }^{2-}$ content in treated samples after $120 \mathrm{~min}$ of reaction. According to this Figure, solution TOC was reduced in a $\sim 30.0 \%$ which indicates that part of the organic matter is being transformed into $\mathrm{CO}_{2}$ and water. In addition, considering Eq. (7) total AZT oxidation also would conduct to $\mathrm{HNO}_{3}$ generation, therefore, an increment on $\mathrm{NO}_{3}^{-}$concentration is expected as it is presented by Fig. 6 .

$$
\mathrm{C}_{38} \mathrm{H}_{72} \mathrm{~N}_{2} \mathrm{O}_{12} \rightarrow \stackrel{\mathrm{SO}_{4}^{-*} / \mathrm{OH}^{\bullet}}{\longrightarrow} \rightarrow \mathrm{CO}_{2}+\mathrm{H}_{2} \mathrm{O}+\mathrm{HNO}_{3}+\mathrm{H}_{2} \mathrm{SO}_{4}
$$

Finally, regarding the increase of sulfate, it would be associated to the $\mathrm{SO}_{4}{ }^{2-}$ formation from $\mathrm{SO}_{4}{ }^{-}$radicals as it is indicated by Eq. (2)-(4).

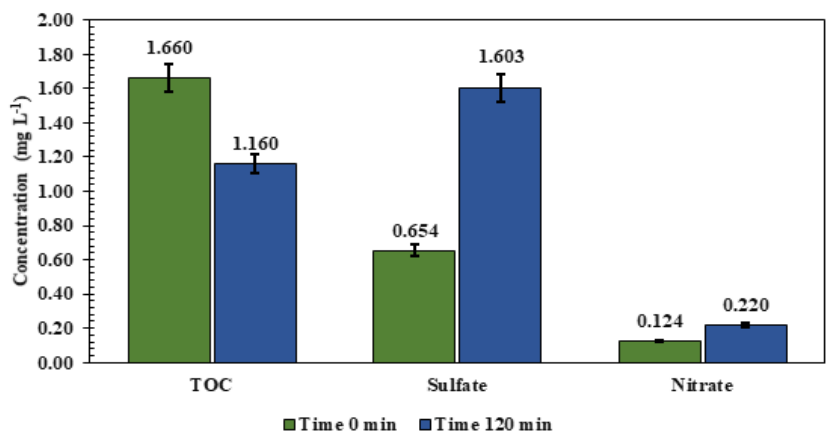

Fig. 6. Total organic carbon (TOC), nitrate and sulfate concentration during AZT removal under optimized conditions using simulated sunlight radiation and PS (pollutant initial concentration $3.0 \mathrm{mg} \mathrm{L}^{-1}$, irradiance $500.0 \mathrm{~W} \mathrm{~m}^{-2}$, pH 9.0, $\mathrm{H}_{2} \mathrm{O}_{2}$ initial PS initial concentration $5.4 \mathrm{mg} \mathrm{L}^{-1}$ ).

\section{Conclusions}

Combination of simulated sunlight radiation and PS is able to remove antibiotic AZT from aqueous matrices. AZT elimination was higher than $\sim 70.0 \%$, and organic matter mineralization was $\sim 30.0 \%$ after 120 min of reaction. 
The conditions that conduct to a higher AZT removal, under the evaluated experimental conditions, are $\mathrm{pH} 9.0$ and $5.4 \mathrm{mg}$ $\mathrm{L}^{-1} \mathrm{~K}_{2} \mathrm{~S}_{2} \mathrm{O}_{8}$ initial concentration. In this aspect, an excess of PS can scavenge $\mathrm{SO}_{4}{ }^{-}$and reduce AZT degradation.

Presence of $\mathrm{SO}_{4} \bullet$ and $\mathrm{OH} \bullet$ radicals on solution was evidenced, and hydroxyl radical, whose generation is favoured under basic $\mathrm{pH}$ conditions, seems to be the primary radical specie dominating the AZT removal.

Finally, AZT elimination, under the evaluated experimental conditions, using simulated sunlight radiation and PS can be described considering a pseudo first-order reaction kinetics model.

\section{Acknowledgment}

Authors thank Universidad de Antioquia for its support for the execution of this project.

\section{Author Contributions}

B.A.O (Undergraduate student) carried out the experiments and reported the results. H.Z. (Ph.D.) supervised the experiments execution, interpreted the results and wrote the manuscript. G.A.P. (Ph.D.) assisted in the results interpretation and the final version of the manuscript preparation.

\section{References}

1. Kanakaraju D, Glass BD, Oelgemöller M. Advanced oxidation process-mediated removal of pharmaceuticals from water: A review. J. Environ. Manage. 2018;219:189-207.

2. Wang J, Zhuan R, Chu L. The occurrence, distribution and degradation of antibiotics by ionizing radiation: An overview. Sci. Total Environ. 2019;646:1385-1397.

3. Wang J, Zhuan R. Degradation of antibiotics by advanced oxidation processes: An overview. Sci. Total Environ. 2020;701: 135023.

4. Sayadi MH, Sobhani S, Shekari H. Photocatalytic degradation of azithromycin using $\mathrm{GO} @ \mathrm{Fe}_{3} \mathrm{O}_{4} / \mathrm{ZnO} / \mathrm{SnO}_{2}$ nanocomposites. J. Clean Prod. 2019;232:127-136.

5. Babić S, Ćurković L, Ljubas D, Čizmić M. $\mathrm{TiO}_{2}$ assisted photocatalytic degradation of macrolide antibiotics. Curr. Opin. Green Sustain. Chem. 2017;6:34-41.

6. Zhou L, Yan C, Sleiman M, Ferronato C, Chovelon JM, Wang $\mathrm{X}$, et al. Sulfate radical induced degradation of B2-adrenoceptor agonists salbutamol and Terbutaline: Implication of halides, bicarbonate, and natural organic matter. Chem. Eng. J. 2019;368:252-260.

7. Zhou L, Sleiman M, Ferronato C, Chovelon JM, de Sainte-Claire P, Richard C. Sulfate radical induced degradation of B2-adrenoceptor agonists salbutamol and terbutaline: Phenoxyl radical dependent mechanisms. Water Res. 2017;123:715-723.

8. Wang J, Wang S. Activation of persulfate (PS) and peroxymonosulfate (PMS) and application for the degradation of emerging contaminants. Chem. Eng. J. 2018;335:1502-1517.

9. Yang Q, Ma Y, Chen F, et al. Recent advances in photo-activated sulfate radical-advanced oxidation process (SR-AOP) for refractory organic pollutants removal in water. Chem. Eng. J. 2019;378:122-149.

10. Marjanovic M, Giannakis S, Grandjean D, de Alencastro LF, Pulgarin C. Effect of MM Fe addition, mild heat and solar UV on sulfate radical-mediated inactivation of bacteria, viruses, and micropollutant degradation in water. Water Res. 2018;140: 220-231.

11. Nie M, Yan C, Xiong X, et al. Degradation of chloramphenicol using a combination system of simulated solar light, $\mathrm{Fe}^{2+}$ and persulfate. Chem. Eng. J. 2018;348:455-463.

12. Bekkouche S, Merouani S, Hamdaoui O, Bouhelassa M. Efficient photocatalytic degradation of Safranin O by integrating solar-UV/ $/ \mathrm{TiO}_{2} /$ persulfate treatment: Implication of sulfate radical in the oxidation process and effect of various water matrix components. J. Photochem. Photobiol. A Chem. 2017;345:80-91.

13. Shokri R, Jalilzadeh YR, Babaei AA, Derikvand E, Almasi A. UV activation of hydrogen peroxide for removal of azithromycin antibiotic from aqueous solution: determination of optimum conditions by response surface methodology. Toxin Rev. 2019.

14. Cano PA, Jaramillo-Baquero M, Zúñiga-Benítez H, Londoño YA, Peñuela GA. Use of simulated sunlight radiation and hydrogen peroxide in azithromycin removal from aqueous solutions Optimization \& mineralization analysis. Emerg. Contam. 2020;6:53-61.

15. Standard Methods for the Examination of Water and Wastewater. 23rd ed. Washington, DC.: American Public Health Association; 2017.

16. Gao YQ, Gao NY, Yin DQ, Tian FX, Zheng QF. Oxidation of the B-blocker propranolol by UV/persulfate: Effect, mechanism and toxicity investigation. Chemosphere 2018;201:50-58.

17. Gu D, Guo C, Lv J, et al. Removal of methamphetamine by UV-activated persulfate: Kinetics and mechanisms. J. Photochem. Photobiol. A Chem. 2019;379:32-38.

18. Gao H, Chen J, Zhang Y, Zhou X. Sulfate radicals induced degradation of Triclosan in thermally activated persulfate system. Chem. Eng. J. 2016;306:522-530.

19. Wojnárovits L, Takács E. Rate constants of sulfate radical anion reactions with organic molecules: A review. Chemosphere 2019;220:1014-1032.

20. Liu C, Chen L, Ding D, Cai T. Sulfate radical induced catalytic degradation of metolachlor: Efficiency and mechanism. Chem. Eng. J. 2019;368:606-617.

21. Feng Y, Song Q, Lv W, Liu G. Degradation of ketoprofen by sulfate radical-based advanced oxidation processes: Kinetics, mechanisms, and effects of natural water matrices. Chemosphere 2017;189:643-651. 